\section{PH STRATEGIES AND CEREBRAL ENERGETICS BEFORE AND AFTER CIRCULATORY ARREST}

The pH-stat strategy compared with the alpha-stat strategy provides more rapid recovery of brain high-energy phosphate stores and intracellular $\mathrm{pH}$ after 1 hour of hypothermic circulatory arrest in pigs. Possible mechanisms for this difference are (1) improved oxygen delivery and homogeneity of brain cooling before deep hypothermic circulatory arrest and (2) greater cerebral blood flow and reduced reperfusion injury owing to extracellular acidosis during the rewarming phase. To identify which of these mechanisms is predominant, we studied 49 4-week-old piglets undergoing 1 hour of deep hypothermic circulatory arrest. Four groups were defined according to cooling/rewarming strategy: alpha/alpha, alpha/pH, pH/alpha, and pH/pH. In 24 animals cerebral high-energy phosphate levels and intracellular pH were measured by magnetic resonance spectroscopy (alpha/alpha group 7 , alpha/pH group 5, pH/alpha group 7, pH/pH group 5). In 25 animals cerebral blood flow was measured by labeled microspheres, cerebral metabolic rate by oxygen and glucose extraction, and the redox state of cytochrome $\mathbf{a a}_{3}$ and hemoglobin oxygenation by near infrared spectroscopy (alpha/alpha group 7, alpha/pH group 5, pH/alpha group 7, $\mathrm{pH} / \mathrm{pH}$ group 6). Cerebral blood flow was greater with pH-stat than alpha-stat during cooling $(56.3 \% \pm 3.7 \%$ versus $32.9 \% \pm 2.1 \%$ of normothermic baseline values, $p<0.001$ ). Cytochrome $a_{3}$ values became more reduced during cooling with alpha-stat than with pH-stat $(p=0.049)$. Recovery of adenosine triphosphate levels in the initial 45 minutes of reperfusion was more rapid in group $\mathrm{pH} / \mathrm{pH}$ compared with that in the other groups $(p=0.029)$. Recovery of cerebral intracellular pH in the initial 30 minutes was faster in group $\mathrm{pH} / \mathrm{pH}$ compared with that in group alpha/alpha $(p=0.026)$. Intracellular pH became more acidic during early reperfusion only in group alpha/alpha, whereas it showed continuous recovery in the other groups. This study suggests that there are mechanisms in effect during both the cooling and rewarming phases before and after deep hypothermic circulatory arrest that could contribute to an improved cerebral outcome with pH-stat relative to more alkaline strategies. (J THORAC CARDIOvaSC SuRG 1995;109:948-58)

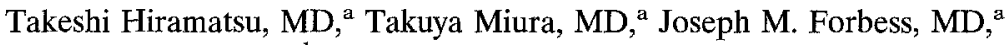
Adre Du Plessis, MD, ${ }^{\mathrm{b}}$ Mitsuru Aoki, MD, ${ }^{\mathrm{a}}$ Fumikazu Nomura, MD, ${ }^{\mathrm{a}}$ David Holtzman, $\mathrm{MD}, \mathrm{PhD},{ }^{b}$ and Richard A. Jonas, MD, Boston, Mass.
A recent retrospective clinical study of cognitive developmental outcome in infants undergoing deep hypothermic circulatory arrest suggested that

From the Departments of Cardiovascular Surgery and Neurology, ${ }^{\mathrm{b}}$ Children's Hospital and Harvard Medical School, Boston, Mass.

Supported in part by National Institutes of Health grant RR00995 and the Cardiovascular Surgery Research Fund at Children's Hospital.

Read at the Twentieth Annual Meeting of The Western Thoracic Surgical Association, Olympic Valley, Calif., June 22-25, 1994.

Address for reprints: Richard A. Jonas, MD, Department of Cardiovascular Surgery, Children's Hospital, 300 Longwood Ave., Boston, MA 02115.

Copyright (C) 1995 by Mosby-Year Book, Inc.

$0022-5223 / 95 \$ 3.00+0 \quad \mathbf{1 2 / 6 / 6 2 9 4 4}$ the alpha-stat strategy of $\mathrm{pH}$ management was associated with less effective cerebral protection compared with the alternative pH-stat strategy. ${ }^{1}$ Another retrospective clinical study of development after circulatory arrest identified association of shorter duration of cooling with worse neurologic outcome after deep hypothermic circulatory arrest. ${ }^{2}$ A parallel laboratory investigation in an immature piglet model of deep hypothermic circulatory arrest demonstrated more rapid recovery of high-energy phosphate levels and intracellular $\mathrm{pH}(\mathrm{pHi})$ with the $\mathrm{pH}$-stat strategy relative to the alpha-stat strategy after 1 hour of deep hypothermic circulatory arrest. ${ }^{3}$

We proposed two possible mechanisms of improved cerebral protection with $\mathrm{pH}$-stat that may contribute to brain protection during the cooling 
phase of cardiopulmonary bypass. The first mechanism is improved oxygen delivery as a result of the rightward shift of the oxyhemoglobin dissociation curve induced by a more acidic strategy, which might counteract the leftward shift induced by hypothermia. ${ }^{4}$ A second proposed mechanism is that the $\mathrm{pH}$-stat method might allow greater total cerebral blood flow with more uniform distribution of that flow resulting in improved homogeneity of brain cooling. Blood $\mathrm{pH}$ differences during the rewarming phase could contribute to the more rapid recovery of cerebral high-energy phosphate stores and pHi. For example, with $\mathrm{pH}$-stat there is greater cerebral blood flow in the early phase of reperfusion and rewarming with improved oxygen delivery. There may be reduced reperfusion injury as a result of extracellular acidosis during the rewarming phase. ${ }^{5,6}$ Various cell culture studies of neuronal hypoxia have shown reduced calcium influx and improved cell survival in the presence of a higher extracellular hydrogen ion concentration, that is, more acidic extracellular $\mathrm{pH}^{7,8}$ Similar findings have been reported in studies of myocardial protection.

To identify whether mechanisms for improved recovery with $\mathrm{pH}$-stat after deep hypothermic circulatory arrest are active during cooling or during rewarming, these strategies were reversed during the cooling and rewarming phases. The results of these crossover studies are compared with those obtained when a uniform $\mathrm{pH}$ strategy was used for both cooling and rewarming. Near infrared spectroscopy was used for in-line assessment of mitochondrial oxygen availability. Magnetic resonance spectroscopy was used for noninvasive assessment of cerebral high-energy phosphate stores and $\mathrm{pHi}$. Radiolabeled microsphere studies were used for measurement of cerebral blood flow and for calculation of cerebral oxygen and glucose consumption.

\section{Material and methods}

Animals. Forty-nine 4-week-old Yucatan miniature piglets, 26 to 31 days old (mean, 29 days) and weighing 2.2 to $4.7 \mathrm{~kg}$ (mean, $3.9 \mathrm{~kg}$ ) were studied (Charles River Laboratories, Wilmington, Mass.). The studies were done in compliance with the "Principles of Laboratory Animal Care" formulated for the National Society for Medical Research and the "Guide for the Care and Use of Laboratory Animals" prepared by the Institute of Laboratory Animal Resources and published by the National Institutes of Health (NIH Publication No. 86-23, revised 1985).

Surgical preparation and perfusion protocol. Details of the surgical preparation and perfusion protocol have been described previously., ${ }^{3,9}$ Briefly, animals were can- nulated through a median sternotomy with an ascending aortic cannula and a single venous cannula in the right atrium. Bypass flow was set at $150 \mathrm{ml} / \mathrm{kg}$ per minute calibrated at a perfusate temperature of $37^{\circ} \mathrm{C}$. To achieve the pH-stat strategy, we maintained $\mathrm{pH}$ at 7.40 corrected to hypothermic body temperature by adjusting the flow of $95 \%$ oxygen and $5 \%$ carbon dioxide to the oxygenator. For alpha-stat, $\mathrm{pH}$ was maintained at 7.40 as measured at $37^{\circ} \mathrm{C}$ by adjustment of the flow of $100 \%$ oxygen. Each piglet was perfused for 20 minutes at normothermia $\left(37^{\circ} \mathrm{C}\right.$ arterial temperature) to stabilize body temperature. Then the perfusate was cooled to an arterial temperature of $14^{\circ} \mathrm{C}$. Ice packs were placed around the head throughout the cooling and circulatory arrest periods. After 30 minutes of perfusion cooling when nasopharyngeal temperature was $14.0^{\circ}$ to $15.0^{\circ} \mathrm{C}$, perfusion was stopped for 1 hour. Reperfusion was begun at a flow rate of $150 \mathrm{ml} / \mathrm{kg}$ per minute with the perfusate at room temperature $\left(20^{\circ} \mathrm{C}\right)$. When normothermia was achieved and reperfusion had been in progress for 45 minutes, ventilation was restarted. Pump perfusion was continued for 3 more hours with the perfusate temperature at $37^{\circ} \mathrm{C}$. During this 3-hour period of perfusion, pulsatile assistance was achieved by raising central venous pressure minimally $(<5 \mathrm{~mm} \mathrm{Hg}$ ). At the end of each study the animal was killed by a bolus injection of Beuthanasia (Schering, Kenilworth, N.J.) and $\mathrm{KCl}$ into the circuit.

Blood flow measurement. Regional blood flow was measured by the radioactive microsphere technique ${ }^{10}$ at 20 minutes after the initiation of cardiopulmonary bypass (normothermic baseline), at 30 minutes after the onset of cooling, and at 5, 45, and 225 minutes after reperfusion. Microspheres $\left(15 \mu \mathrm{m}\right.$ diameter) were labeled with ${ }^{141} \mathrm{Ce}$, ${ }^{113} \mathrm{Sn},{ }^{85} \mathrm{Sr},{ }^{95} \mathrm{Nb}$, or ${ }^{46} \mathrm{Sc}$. At the termination of the experiment, the brain was taken out and weighed. It was divided into five parts, that is, the cerebral hemispheres, basal ganglia, midbrain, cerebellum, and brain stem (pons and medulla oblongata). The organs were dissolved in $2 \mathrm{~N} \mathrm{KOH}-m e t h a n o l$ solution and the radioactivity was counted in a gamma counter (Compugamma 1282; LKB Instruments Inc., Wallac, Finland).

Metabolic measurements. Blood gas tensions and $\mathrm{pH}$, hemoglobin, plasma glucose, and lactate levels were measured in arterial, jugular venous, and mixed venous blood before cardiopulmonary bypass and after each microsphere injection. Blood gas levels and hemoglobin were measured with a blood gas analyzer (model 278; Ciba Corning, Corning, N.Y.). Plasma glucose and lactate levels were determined by the glucose oxidase method and enzymatic fluorometric micromethod, respectively.

Cerebral oxygen consumption $\left(\mathrm{CMR}-\mathrm{O}_{2}\right)$ and glucose consumption (CMR-gluc) were calculated from the total cerebral blood flow and the difference between the arterial and internal jugular venous oxygen contents and glucose concentrations.

Magnetic resonance spectroscopy. The details of the techniques used in this study have been described previously.9 Relative concentrations of inorganic phosphate (Pi), creatine phosphate $(\mathrm{PCr})$, and adenosine triphosphate (ATP) were determined from peak areas obtained by Lorentzian curve fitting and peak integration. Changes 
in the ATP concentration were assessed from the $\beta$-nucleoside triphosphate peak. The Pi, PCr, and ATP data are reported as percentage of the full-flow normothermic values after 20 minutes of bypass. The pHi in the brain was calculated from the chemical shift of the Pi peak relative to the $\mathrm{PCr}$ peak. ${ }^{11}$

Near infrared spectroscopy. A near infrared spectrometer (NIRO-5; Hamamatsu Photonics KK, Hamamatsu, Japan) was used for this study. Small areas of the scalp were excised and plastic collars were glued directly to the skull. Fiberoptic optodes for transmission of laser light of near infrared wavelengths and for photon detection were secured to the collars with plastic screws. The optode spacing was 3.0 to $3.5 \mathrm{~cm}$ on the skull with the optodes on the skull in a coronal plane. The animal then was placed in a supine position with the head placed on a pillow designed to protect the optodes. Relative concentration changes in oxygenated hemoglobin, reduced hemoglobin, and oxidized cytochrome $\mathrm{aa}_{3}$ were collected continuously from after anesthesia induction to the end of experiment.

Experimental design. Four groups were defined according to $\mathrm{pH}$ strategy used during cooling and rewarming: alpha/alpha (group A-A), alpha/pH (group A-P), $\mathrm{pH} / \mathrm{alpha}$ (group P-A), and $\mathrm{pH} / \mathrm{pH}$ (group P-P). In 25 piglets (A-A 7, A-P 5, P-A 7, P-P 6), cerebral metabolic rate determined by arteriovenous differences in oxygen and glucose, blood flow by radioactive microspheres, and near infrared spectroscopic measures of the redox state of cytochrome $\mathrm{aa}_{3}$, as well as total (oxygenated hemoglobin + reduced hemoglobin), oxygenated, and reduced cerebral hemoglobin concentration, were studied. Measurements were made at the end of normothermic perfusion, at the end of cooling, and at 5, 45, and 225 minutes after reperfusion. Another set of 24 animals (A-A 7, A-P 5, P-A 7 , P-P 5) that underwent the same surgical and bypass procedures were studied by phosphorus 31-magnetic resonance spectroscopy.

Statistics. All values are reported as mean plus or minus the standard error of the mean and were analyzed by means of a statistical analysis system (SPSS; SPSS Inc., Chicago, Ill.). Repeated-measures analysis of variance and Student-Newman-Keuls test was used to detect differences between groups. A $p$ value less than 0.05 was considered significant.

\section{Results}

Unless noted otherwise, all blood $\mathrm{pH}$, carbon dioxide tension, and oxygen tension values are reported without body temperature correction as measured at $37^{\circ} \mathrm{C}$. The data reported as percentages were calculated as a percentage of the results at the end of the initial normothermic cardiopulmonary bypass period (baseline: 100\%).

The total systemic flow calculated from the total radioactivity in each injection and the reference blood correlated well with the pump flow measured by the electromagnetic flowmeter $(y=0.97 x+24.1$, $r=0.9463, p=0.0001$ ).
Experimental conditions and baseline values ( $\mathrm{Ta}$ bles I and II). No significant differences were detected among the four groups in mean blood pressure, arterial oxygen and carbon dioxide tensions, and nasopharyngeal and rectal temperatures at baseline cardiopulmonary bypass measurements. Nasopharyngeal temperature was approximately $15^{\circ} \mathrm{C}$ at the end of cooling and recovered to approximately $36^{\circ} \mathrm{C}$ after 45 minutes of reperfusion. Rectal temperature decreased to approximately $20^{\circ} \mathrm{C}$ at the end of cooling, recovered to around $34^{\circ} \mathrm{C}$ at 45 minutes of reperfusion, and then returned to $36^{\circ} \mathrm{C}$. There were no significant differences among groups. Group A-A had a lower blood pressure at 3 hours of normothermic reperfusion than was found in groups P-P and P-A $(p=0.016)$. There were also no significant differences among the four groups in cerebral blood flow, cerebrovascular resistance, cerebral metabolic rates of oxygen and glucose, systemic lactate level, and systemic blood flow at baseline during bypass.

Cerebral high-energy phosphates and pHi. Initiation of normothermic cardiopulmonary bypass did not affect the prebypass values of ATP (Fig. 1, $A$ ), PCr (Fig. 1, $B$ ), or pHi (Fig. 1, $C$ ). Both ATP and $\mathrm{PCr}$ values increased during cooling in all groups and there was no significant difference among groups. The pHi increased during cooling from $7.07 \pm 0.03$ to $7.60 \pm 0.04(p<0.001)$ in the alpha-stat groups and from $7.10 \pm 0.03$ to $7.29 \pm 0.04(p=0.001)$ in the $\mathrm{pH}$-stat groups. The $\mathrm{pHi}$ was significantly more alkaline in the alpha-stat cooling groups than in the $\mathrm{pH}$-stat cooling groups $(p<0.001)$.

The ATP and PCr concentrations became unmeasurable by nuclear magnetic resonance within 36 minutes of the beginning of circulatory arrest. The pHi decreased during circulatory arrest, but was not measurable during the latter 40 minutes of circulatory arrest and the initial 9 minutes of reperfusion because of the loss of PCr peaks. The mean recovery rate of ATP levels was significantly faster in the first 45 minutes of reperfusion in group P-P and was $2.42 \% \pm 0.41 \% / \mathrm{min}(p=0.029)$ compared with that in the other three groups $(1.02 \% \pm 0.37 \% / \mathrm{min}$ in group $\mathrm{A}-\mathrm{A}, 1.16 \% \pm 0.22 \% / \mathrm{min}$ in group $\mathrm{A}-\mathrm{P}$, and $1.26 \% \pm 0.21 \% / \mathrm{min}$ in group P-A). The mean recovery rate of $\mathrm{pHi}$ was significantly faster in the first 30 minutes of reperfusion in group P-P and was $0.290 \pm 0.09 \mathrm{unit} / \mathrm{min}(p=0.026)$ versus $-0.034 \pm$ $0.07 \mathrm{unit} / \mathrm{min}$ in group A-A. The pHi decreased during the first 27 minutes of reperfusion in group A-A, which was not observed in the other three 
Table I. Experimental conditions

\begin{tabular}{|c|c|c|c|c|c|c|c|c|}
\hline Parameter & Group & $\begin{array}{l}\text { Before } \\
\text { bypass }\end{array}$ & $C P B(20)$ & $H T(30)$ & $R P(0)$ & $R P(5)$ & $N T(0)$ & $N T(180)$ \\
\hline \multirow[t]{4}{*}{ Arterial $\mathrm{pH}$} & A-A & $7.46 \pm 0.01$ & $7.39 \pm 0.01$ & $7.40 \pm 0.01$ & & $7.40 \pm 0.01$ & $7.33 \pm 0.01$ & $7.37 \pm 0.01$ \\
\hline & A-P & $7.48 \pm 0.02$ & $7.41 \pm 0.01$ & $7.39 \pm 0.01$ & & $7.14 \pm 0.02^{*}$ & $7.35 \pm 0.01 *$ & $7.39 \pm 0.01$ \\
\hline & P-P & $7.44 \pm 0.02$ & $7.38 \pm 0.01$ & $7.05 \pm 0.01 \dagger$ & & $7.16 \pm 0.01^{*}$ & $7.35 \pm 0.01^{*}$ & $7.36 \pm 0.02$ \\
\hline & P-A & $7.43 \pm 0.02$ & $7.39 \pm 0.02$ & $7.04 \pm 0.01 \dagger$ & & $7.36 \pm 0.02$ & $7.41 \pm 0.01$ & $7.37 \pm 0.01$ \\
\hline \multirow[t]{4}{*}{ Arterial $\mathrm{PCO}_{2}(\mathrm{~mm} \mathrm{Hg})$} & A-A & $40.1 \pm 1.0$ & $43.3 \pm 1.2$ & $40.6 \pm 1.5$ & & $39.5 \pm 1.8$ & $39.2 \pm 1.2$ & $43.0 \pm 1.0$ \\
\hline & A-P & $38.2 \pm 1.4$ & $42.0 \pm 0.3$ & $40.5 \pm 1.8$ & & $68.9 \pm 3.6^{*}$ & $44.4 \pm 1.5^{*}$ & $41.4 \pm 1.5$ \\
\hline & P-P & $38.4 \pm 1.8$ & $43.6 \pm 1.4$ & $99.5 \pm 1.7 \dagger$ & & $66.9 \pm 2.5^{*}$ & $44.8 \pm 0.9^{*}$ & $43.3 \pm 1.3$ \\
\hline & P-A & $38.9 \pm 1.5$ & $40.4 \pm 2.7$ & $98.5 \pm 1.9 \dagger$ & & $40.5 \pm 1.2$ & $40.4 \pm 1.1$ & $41.6 \pm 1.8$ \\
\hline \multirow[t]{4}{*}{ Arterial $\mathrm{Po}_{2}(\mathrm{~mm} \mathrm{Hg})$} & A-A & $479 \pm 37$ & $406 \pm 32$ & $768 \pm 33$ & & $367 \pm 34$ & $444 \pm 37$ & $464 \pm 28$ \\
\hline & A-P & $509 \pm 27$ & $344 \pm 29$ & $808 \pm 26$ & & $360 \pm 29$ & $444 \pm 31$ & $476 \pm 28$ \\
\hline & P-P & $502 \pm 37$ & $327 \pm 39$ & $778 \pm 52$ & & $408 \pm 47$ & $352 \pm 42$ & $382 \pm 31$ \\
\hline & P-A & $506 \pm 43$ & $416 \pm 36$ & $754 \pm 60$ & & $401 \pm 33$ & $405 \pm 34$ & $459 \pm 45$ \\
\hline \multirow[t]{4}{*}{ Hematocrit $(\%)$} & $A-A$ & $33.5 \pm 1.4$ & $24.3 \pm 0.8$ & $22.1 \pm 0.9$ & & $22.6 \pm 0.7$ & $21.9 \pm 0.8$ & $18.7 \pm 0.9$ \\
\hline & A-P & $33.6 \pm 0.9$ & $25.0 \pm 1.0$ & $23.6 \pm 1.2$ & & $23.4 \pm 1.3$ & $22.4 \pm 0.9$ & $20.2 \pm 1.1$ \\
\hline & P-P & $34.9 \pm 0.8$ & $23.6 \pm 1.3$ & $22.4 \pm 1.2$ & & $22.5 \pm 1.1$ & $21.8 \pm 0.9$ & $18.8 \pm 1.3$ \\
\hline & P-A & $32.0 \pm 1.4$ & $23.0 \pm 1.2$ & $21.8 \pm 0.8$ & & $21.3 \pm 0.6$ & $21.8 \pm 1.1$ & $18.6 \pm 1.7$ \\
\hline \multirow[t]{4}{*}{ NP temperature $\left({ }^{\circ} \mathrm{C}\right)$} & $A-A$ & $36.6 \pm 0.4$ & $36.3 \pm 0.2$ & $14.6 \pm 0.4$ & $17.9 \pm 0.4$ & $28.9 \pm 0.4$ & $36.2 \pm 0.2$ & $36.3 \pm 0.2$ \\
\hline & A-P & $36.9 \pm 0.4$ & $37.2 \pm 0.1$ & $14.7 \pm 0.5$ & $18.7 \pm 0.6$ & $28.0 \pm 0.7$ & $36.7 \pm 0.3$ & $36.9 \pm 0.2$ \\
\hline & P-P & $37.5 \pm 0.4$ & $36.7 \pm 0.2$ & $13.8 \pm 0.2$ & $18.0 \pm 0.4$ & $28.1 \pm 0.3$ & $36.6 \pm 0.3$ & $36.8 \pm 0.2$ \\
\hline & P-A & $36.6 \pm 0.4$ & $36.2 \pm 0.4$ & $15.1 \pm 0.5$ & $19.3 \pm 0.4$ & $28.0 \pm 1.4$ & $36.0 \pm 0.3$ & $36.4 \pm 0.2$ \\
\hline \multirow[t]{4}{*}{ Rectal temperature $\left({ }^{\circ} \mathrm{C}\right)$} & A-A & $37.0 \pm 0.4$ & $36.9 \pm 0.2$ & $20.1 \pm 1.3$ & $24.3 \pm 0.9$ & $29.8 \pm 0.7$ & $35.6 \pm 0.4$ & $36.4 \pm 0.5$ \\
\hline & A-P & $37.0 \pm 0.4$ & $37.1 \pm 0.3$ & $20.4 \pm 0.8$ & $25.1 \pm 0.5$ & $28.1 \pm 0.6$ & $35.2 \pm 0.4$ & $36.7 \pm 0.3$ \\
\hline & P-P & $37.9 \pm 0.6$ & $37.3 \pm 0.2$ & $19.0 \pm 1.2$ & $24.3 \pm 1.3$ & $28.2 \pm 0.5$ & $35.4 \pm 0.3$ & $37.5 \pm 0.2$ \\
\hline & P-A & $36.4 \pm 0.3$ & $36.4 \pm 0.4$ & $20.7 \pm 1.3$ & $25.6 \pm 0.5$ & $28.8 \pm 0.4$ & $34.8 \pm 0.5$ & $36.1 \pm 0.6$ \\
\hline \multirow{4}{*}{$\begin{array}{l}\text { Mean blood pressure } \\
\quad(\mathrm{mm} \mathrm{Hg})\end{array}$} & A-A & $92 \pm 5$ & $67 \pm 4$ & $84 \pm 5$ & & $52 \pm 4$ & $65 \pm 3$ & $116 \pm 2 \ddagger$ \\
\hline & A-P & $86 \pm 4$ & $65 \pm 5$ & $82 \pm 6$ & & $51 \pm 3$ & $62 \pm 7$ & $130 \pm 6$ \\
\hline & P-P & $96 \pm 4$ & $62 \pm 4$ & $76 \pm 5$ & & $47 \pm 3$ & $74 \pm 4$ & $134 \pm 2$ \\
\hline & P-A & $89 \pm 3$ & $56 \pm 4$ & $72 \pm 4$ & & $47 \pm 3$ & $66 \pm 6$ & $124 \pm 4$ \\
\hline
\end{tabular}

Data are given as mean plus or minus standard error of the mean. Arterial $\mathrm{pH}$ and carbon dioxide tension followed each strategy of $\mathrm{pH}$ management. Before bypass, Before initiation of cardiopulmonary bypass; $C P B(20), 20$ minutes after initiation of cardiopulmonary bypass; $H T$, hypothermic cardiopulmonary bypass; $R P(0)$, just before reperfusion; $R P(5), 5$ minutes after reperfusion; $N T(0)$, after 45 minutes of rewarming/reperfusion; $N T(180)$, after 180 minutes of normothermic reperfusion following 45 minutes of rewarming/reperfusion; $\mathrm{PCO}_{2}$, carbon dioxide tension; $\mathrm{PO}_{2}$, oxygen tension; $\mathrm{NP}$, nasopharyngeal.

${ }^{*} p<0.01$ versus groups A-A and P-A.

$t p<0.01$ versus groups A-A and A-P.

$\ddagger p<0.05$ versus groups P-A and P-P.

groups. The final recovery of ATP levels was $81.0 \% \pm$ $7.1 \%$ in group $\mathrm{A}-\mathrm{A}, 70.8 \% \pm 3.0 \%$ in group A-P, $92.4 \% \pm 15.8 \%$ in group P-P, and $71.1 \% \pm 3.5 \%$ in group P-A with no significant differences between groups. The pHi and $\mathrm{PCr}$ values also demonstrated no significant differences between groups.

Cerebral blood flow, CMR-O , and CMR-gluc. The cerebral blood flow (Fig. 2) decreased during cooling, but the total flow expressed as a percent change from baseline was greater in the $\mathrm{pH}$-stat cooling groups $(56.5 \% \pm 3.7 \%)$ than in the alphastat cooling groups $(32.9 \% \pm 2.1 \%)(p=0.001)$. The vascular resistance was lower in the $\mathrm{pH}$-stat cooling groups $(212 \% \pm 27 \%)$ than in the alpha-stat cooling groups $(386 \% \pm 37 \%)(p=0.001)$. At 5 minutes of reperfusion, the blood flow in group A-A was lower than that in group A-P and the flow in group P-P was higher than that in group P-A, but these differences did not achieve significance. Although blood flow remained depressed after 45 minutes of reperfusion and rewarming in all groups, by 225 minutes cerebral blood flow had returned to baseline levels without any differences among groups.

Regional blood flow in the brain (Fig. 3) was significantly greater in the $\mathrm{pH}$-stat groups relative to that in the alpha-stat groups during cooling in the basal ganglia, midbrain, and cerebellum $(p<0.001)$. At 5 minutes of rewarming and reperfusion, the regional blood flows in the midbrain in groups P-P and A-P were significantly greater than those in group A-A $(p=0.049)$, and the flow in the brain stem in group $\mathrm{P}-\mathrm{P}$ was significantly greater than that in groups $\mathrm{A}-\mathrm{A}$ and $\mathrm{P}-\mathrm{A}(p=0.05)$.

At all times there were minimal differences among the groups in cerebral oxygen (Fig. 4) and 

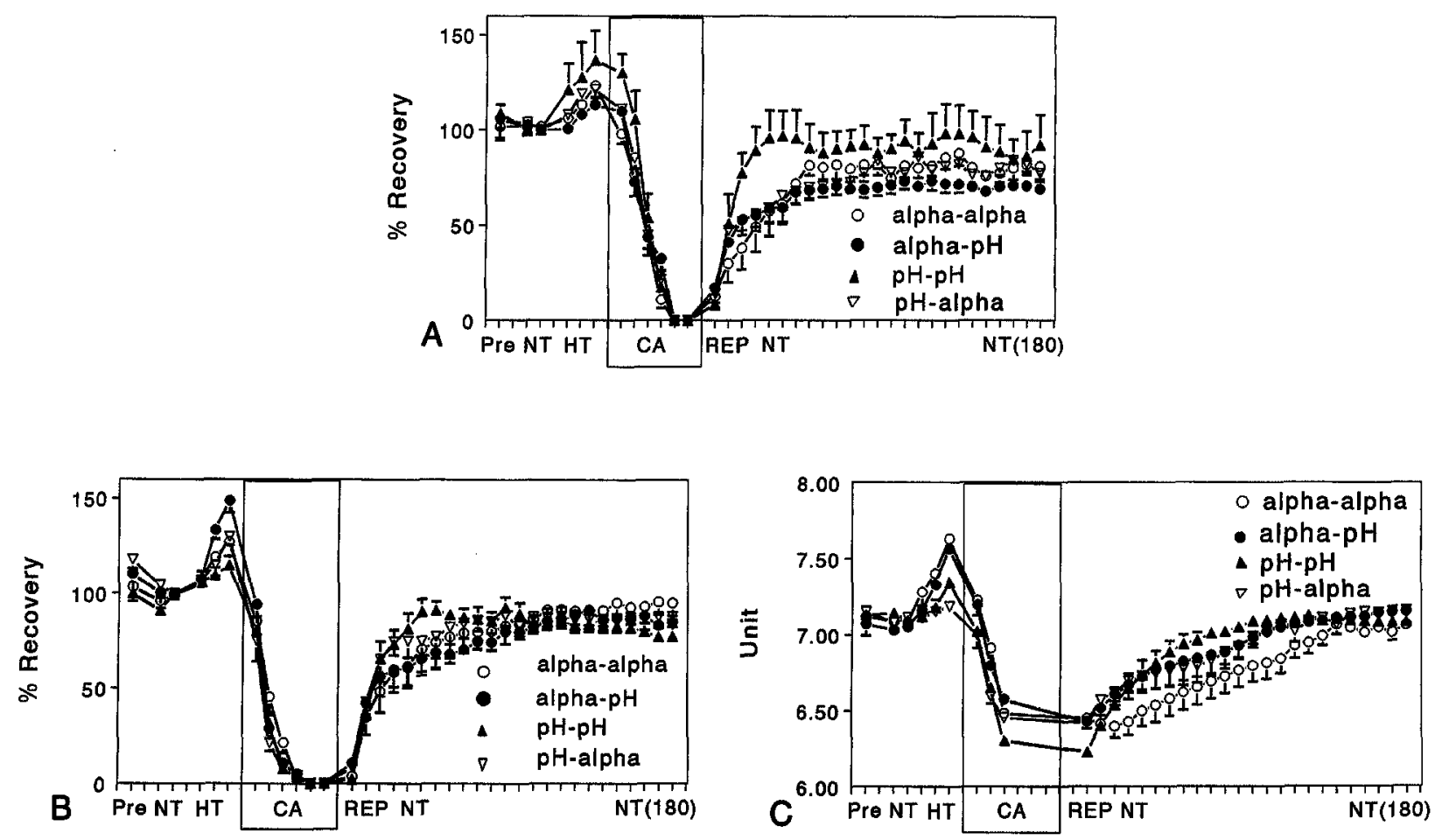

Fig. 1. Cerebral high-energy phosphate levels and pHi by magnetic resonance spectroscopy. A, Percent recovery of cerebral ATP levels. B, Percent recovery of PCr. C, Recovery of pHi. NT, Normothermic cardiopulmonary bypass; $H T$, hypothermic cardiopulmonary bypass; $C A$, circulatory arrest; $R E P$, reperfusion and rewarming; $N T(180)$, normothermia for 180 minutes. See text for details.

Table II. Baseline values for blood flow and metabolism

\begin{tabular}{lcccc}
\hline \multicolumn{1}{c}{ Parameters } & Group A-A & Group A-P & Group P-P & Group P-A \\
\hline Cerebral blood flow $(\mathrm{mL} / \mathrm{min}$ per $100 \mathrm{gm}$ tissue) & $56.6 \pm 5.0$ & $53.5 \pm 5.5$ & $55.5 \pm 2.7$ & $56.2 \pm 3.2$ \\
Cerebrovascular resistance $(\mathrm{mm} \mathrm{Hg} \times \mathrm{min} / \mathrm{ml} \times 100 \mathrm{gm}$ tissue) & $1.16 \pm 1.10$ & $1.23 \pm 0.11$ & $1.06 \pm 0.12$ & $1.20 \pm 0.04$ \\
$\mathrm{CMR}_{2}(\mu \mathrm{O} / \mathrm{min}$ per $100 \mathrm{gm}$ tissue) & $3.51 \pm 0.52$ & $3.02 \pm 0.46$ & $3.23 \pm 0.44$ & $3.01 \pm 0.31$ \\
CMR-gluc $(\mathrm{mg} / \mathrm{min}$ per $100 \mathrm{gm}$ tissue) & $8.59 \pm 2.02$ & $8.43 \pm 1.54$ & $8.19 \pm 1.51$ & $8.35 \pm 1.76$ \\
Systemic oxygen consumption $(\mu \mathrm{l} / \mathrm{min}$ per kg) & $6.31 \pm 0.27$ & $6.80 \pm 0.45$ & $6.12 \pm 0.24$ & $6.44 \pm 0.26$ \\
Systemic lactate level $(\mathrm{mmol} / \mathrm{L})$ & $2.61 \pm 0.17$ & $3.08 \pm 0.14$ & $3.01 \pm 0.47$ & $2.67 \pm 0.28$ \\
Regional blood flow $(\mathrm{ml} / \mathrm{min}$ per 100 gm tissue) & & & \\
Heart & $206.0 \pm 23.5$ & $223.7 \pm 22.4$ & $216.4 \pm 19.8$ & $205.4 \pm 11.7$ \\
Kidney & $168.6 \pm 12.9$ & $155.8 \pm 23.2$ & $170.0 \pm 19.7$ & $163.7 \pm 13.3$ \\
Liver (hepatic arterial) & $85.8 \pm 5.4$ & $78.2 \pm 2.2$ & $88.0 \pm 13.0$ & $79.7 \pm 6.4$ \\
Intestine & $35.5 \pm 2.7$ & $34.3 \pm 4.5$ & $39.8 \pm 5.0$ & $37.2 \pm 3.8$ \\
Lung (bronchial) & $4.3 \pm 1.4$ & $4.8 \pm 0.5$ & $4.4 \pm 0.6$ & $4.0 \pm 0.6$ \\
Adrenal glands & $508.0 \pm 38.1$ & $427.0 \pm 35.6$ & $433.47 \pm 53.2$ & $460.6 \pm 40.8$ \\
Carcass & $7.5 \pm 0.6$ & $7.7 \pm 1.5$ & $7.4 \pm 0.6$ & $7.1 \pm 0.5$ \\
\hline
\end{tabular}

glucose consumption (data not shown). Cooling was associated with a decrease in CMR- $\mathrm{O}_{2}$ and CMRgluc to approximately $15 \%$ of baseline values. Like cerebral blood flow, CMR-O $\mathrm{O}_{2}$ and CMR-gluc remained depressed when normothermia was first regained but after 225 minutes of reperfusion baseline values were regained in all groups.
Near infrared spectroscopy. Data suitable for analysis were available from group A-P and P-A animals. The initiation of bypass was associated with hemodilution by the prime solution in the bypass circuit. The resultant hematocrit values are listed in Table I. Hemodilution was reflected in a fall in oxygenated hemoglobin, reduced hemoglobin, and 


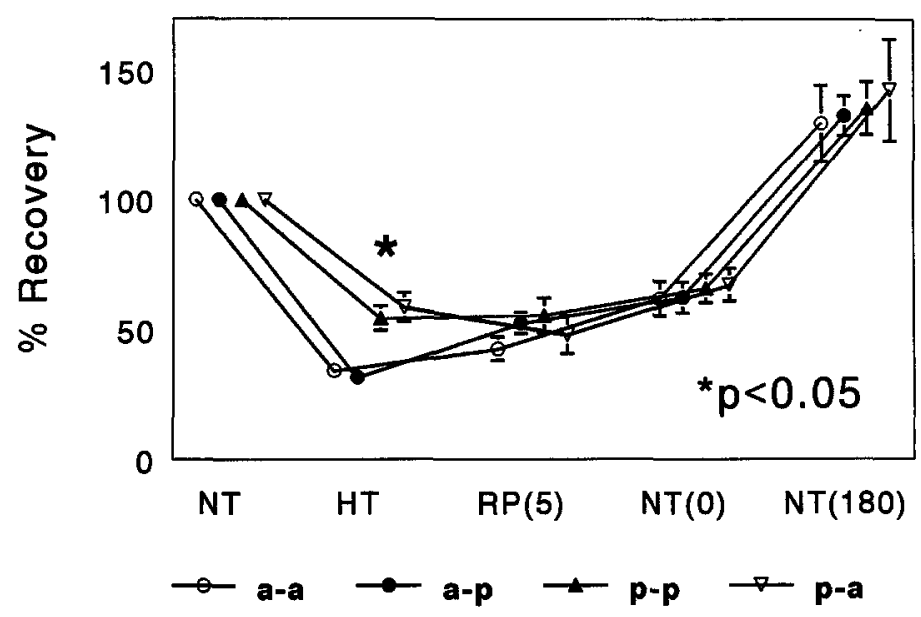

Fig. 2. Cerebral blood flow by microsphere technique. Percent recovery of cerebral blood flow. NT, Normothermic cardiopulmonary bypass; $H T$, hypothermic cardiopulmonary bypass; $R P(5), 5$ minutes after reperfusion and rewarming; $N T(0)$, after 45 minutes of rewarming, when normothermia (nasopharyngeal temperature $>35^{\circ} \mathrm{C}$ ) was achieved; $N T(180)$, normothermia for 180 minutes; *Blood flow in pH-stat cooling groups is significantly greater than that in alpha-stat cooling groups $(p<0.05)$.

oxygenated hemoglobin + reduced hemoglobin, which did not stabilize until 12 minutes after the onset of bypass. At the baseline point of hypothermic cardiopulmonary bypass (NT on Fig. 5) after 20 minutes of normothermic bypass, the near infrared spectroscopy signals were stable.

Cytochrome aa 3 (Fig. $5, A$ ) became more reduced during cooling in the alpha-stat $(-2.18 \pm 0.54$ $\mu \mathrm{mol} / \mathrm{L} \times$ differential pathlength factor) cooling group than in the $\mathrm{pH}$-stat $(-0.72 \pm 0.31 \mu \mathrm{mol} / \mathrm{L} /$ differential pathlength factor) cooling group ( $p=$ 0.049 ). During circulatory arrest there was a continuing decline in the degree of oxidation of cytochrome $\mathrm{aa}_{3}$ (increasing reduction), which did not plateau. During reperfusion there was a gradual return toward baseline values with no intergroup differences. In both groups the signal remained below baseline values.

Total hemoglobin values (oxygenated hemoglobin + reduced hemoglobin) (data not shown) decreased during cooling in the $\mathrm{pH}$-stat group less than those in the alpha-stat group, but the difference did not achieve significance $(p=0.751)$. During circulatory arrest the total hemoglobin value decreased to below baseline in both groups. It gradually returned toward baseline during reperfusion and exceeded baseline after 3 hours of normothermic perfusion in both groups.

Oxygenated hemoglobin values (Fig. 5, B) tended to increase during cooling in the alpha-stat group more than in the pH-stat group. After the onset of circulatory arrest there was progressive desaturation. The oxygenated hemoglobin signal plateaued 30 minutes after the onset of circulatory arrest. After reperfusion there was a gradual return of the oxygenated hemoglobin signal toward baseline values.

The reduced hemoglobin value decreased during cooling in both groups. It increased during circulatory arrest to greater than baseline but returned to baseline levels after 45 minutes of reperfusion in both groups (Fig. 5, C).

Systemic oxygen consumption and lactate level. Systemic oxygen consumption decreased to approximately $25 \%$ of baseline values during cooling and recovered to baseline values after 3 hours of normothermic perfusion in all groups. There were no differences between groups at any measurement (data not shown). Systemic lactate level in group A-A tended to be higher than that in group A-P after reperfusion. When the lactate values were compared between these two groups, the difference achieved significance at 5 minutes of reperfusion. Similarly, the lactate level in group P-A had a tendency to be higher than that in group P-P after reperfusion. When these two groups were compared, the difference achieved significance at 45 minutes of reperfusion (data not shown).

Regional blood flow. The regional blood flow to the kidney was greater in the alpha-stat groups $(75.8 \% \pm 6.2 \%)$ than in the $\mathrm{pH}$-stat groups $(48.5 \% \pm$ $6.9 \%)$ at the end of cooling $(p=0.008)$. The renal 


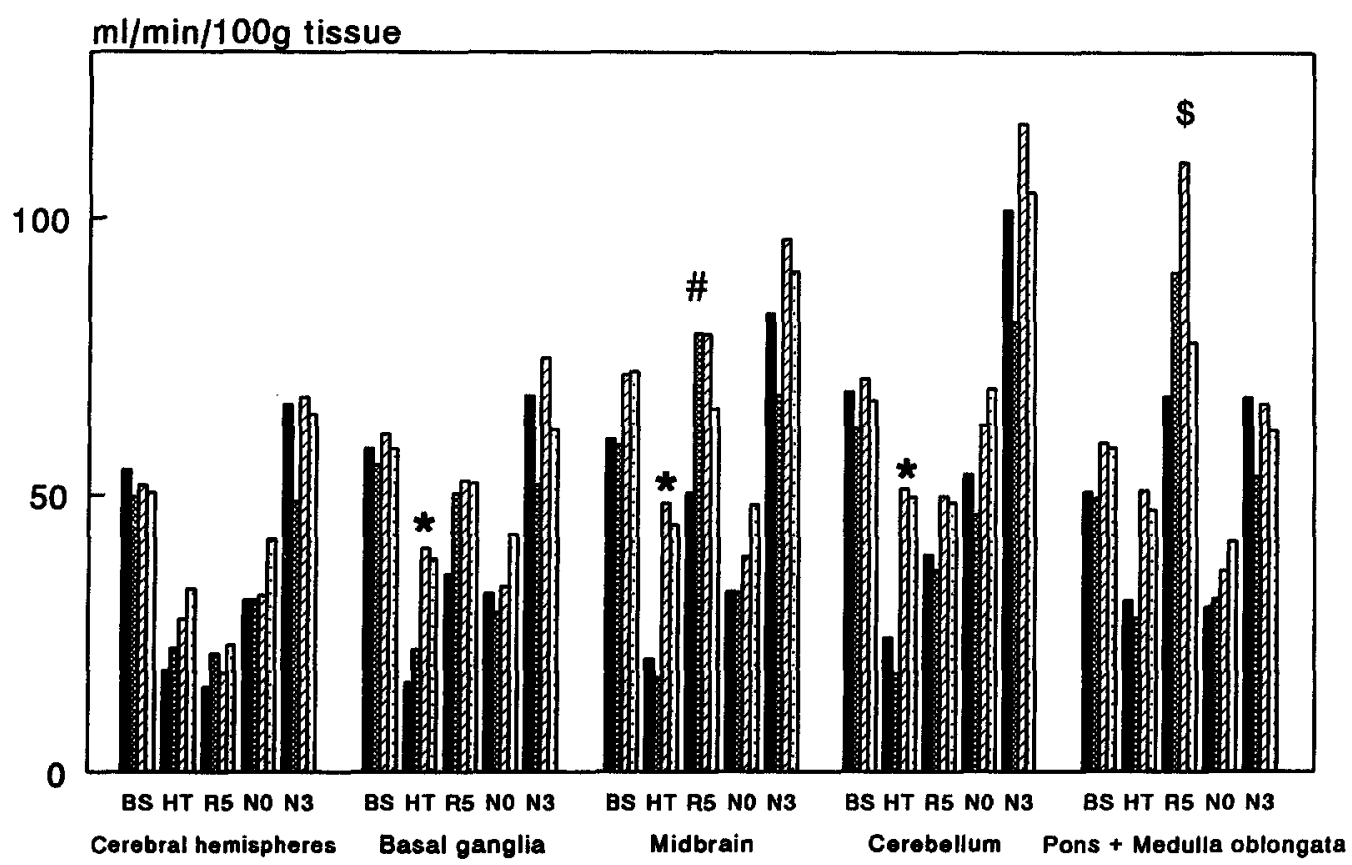

Fig. 3. Regional cerebral blood flow. $B S$, Baseline during normothermic bypass; $H T$, at end of 30 minutes of hypothermic cardiopulmonary bypass; $R 5,5$ minutes after reperfusion and rewarming; $N O$, after 45 minutes of rewarming, when normothermia (nasopharyngeal temperature $>35^{\circ} \mathrm{C}$ ) was achieved; $N 3$, normothermia for 3 hours; *regional blood flow in $\mathrm{pH}$-stat cooling groups is significantly greater than that in alpha-stat cooling groups; \#blood flow in groups P-P and A-P is significantly greater than that in group A-A $(p<0.05)$; \$blood flow in group P-P is significantly greater than that in group A-A $(p<0.05)$.

blood flow recovered to the baseline value in all groups after 3 hours of normothermic perfusion. There was no significant difference in urinary output (data not shown) at any stage. The blood flow to the adrenal glands was greater in the $\mathrm{pH}$-stat groups $(84.6 \% \pm 4.4 \%)$ than in the alpha-stat groups $(61.9 \% \pm 5.5 \%)$ with cooling $(p=0.004)$. Blood flow to the lung was greater in group A-A $(731.5 \% \pm$ $169.0 \%)$ than in the other three groups $(322.6 \% \pm$ $29.4 \%$ in group A-P, $411.7 \% \pm 64.1 \%$ in group P-P, and $382.2 \% \pm 44.2 \%$ in group $\mathrm{P}-\mathrm{A})$ at 45 minutes of reperfusion $(p=0.039)$. In other organs the blood flows were similar at all measurements.

Body weight gain. Body weight gain was the same in all groups.

Brain water content. Water content in the brain was $81.3 \% \pm 0.2 \%$ in group $\mathrm{A}-\mathrm{A}, 81.2 \% \pm 0.2 \%$ in group A-P, $80.8 \% \pm 0.3 \%$ in group P-P, and $80.8 \% \pm$ $0.3 \%$ in group $\mathrm{P}-\mathrm{A}(p=0.310)$.

\section{Discussion}

This study demonstrates more rapid recovery of cerebral ATP levels when the pH-stat strategy is used both before and after deep hypothermic circulatory arrest compared with use of alpha-stat during the cooling and/or rewarming phases. Cerebral pHi decreased during the first 40 minutes of rewarming and reperfusion only when alpha-stat was applied during both the cooling and rewarming phases. Global and regional cerebral blood flow was greater with $\mathrm{pH}$-stat during cooling and was also greater during rewarming with $\mathrm{pH}$-stat, irrespective of the strategy used during cooling. Near infrared spectroscopy revealed greater reduction of cytochrome $\mathrm{aa}_{3}$ values with alpha-stat during cooling.

The alpha-stat strategy of $\mathrm{pH}$ management during hypothermia is based on the premise that cellular function is best preserved by maintenance of neutral $\mathrm{pH}$ appropriate to the temperature of the cell. To 


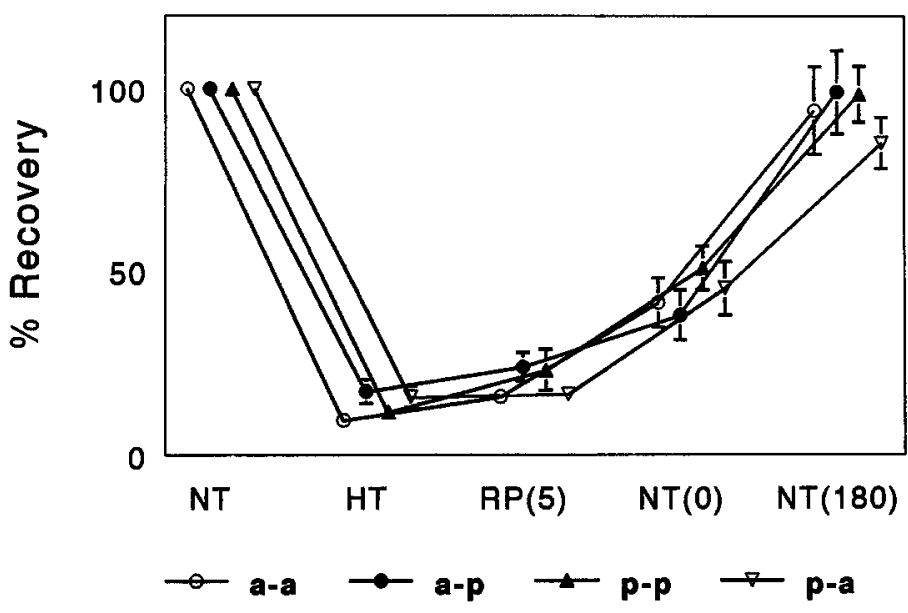

Fig. 4. Cerebral metabolic rate. Percent recovery of $\mathrm{CMR}-\mathrm{O}_{2}$. Abbreviations as in Fig. 2.

achieve this, the $\mathrm{pH}$ is allowed to rise naturally with cooling so that, at a temperature of $20^{\circ} \mathrm{C}$, the $\mathrm{pH}$ measured at $20^{\circ} \mathrm{C}$ is approximately 7.70 . Measured at $37^{\circ} \mathrm{C}$, the $\mathrm{pH}$ will always be 7.40 when the alpha-stat method is used. ${ }^{12}$ This strategy has the potential disadvantage that oxygen availability may be restricted because of the leftward shift in the oxyhemoglobin dissociation curve. This effect exacerbates the leftward shift induced by deep hypothermic temperatures. The reduction in cytochrome $\mathrm{aa}_{3}$ signal noted by near infrared spectroscopy during cooling suggests decreased cellular oxygen availability. This occurs at a time when areas of the brain may still be quite warm with a high metabolic rate.

An alkaline shift in pHi was noted with both the alpha-stat and $\mathrm{pH}$-stat strategies during cooling despite the different extracellular $\mathrm{pH}$. We have noted this effect in previous studies, ${ }^{3}$ and this finding is similar to those in reports by Swain and colleagues in sheep. ${ }^{13}$ Swain and colleagues ${ }^{13}$ proposed the hypothesis that brain pHi is actively regulated to maintain an alpha-stat intracellular environment independent of blood $\mathrm{pH}$. This effect decreases the rationale for the use of alpha-stat if intracellular enzyme systems will be exposed to an alpha-stat environment to some extent irrespective of the extracellular milieu during hypothermia. Nevertheless there is another reason alpha-stat may be the more appropriate strategy when moderately hypothermic cardiopulmonary bypass is used without deep hypothermic circulatory arrest. Probably the most important source of cerebral morbidity associated with the use of full-flow cardiopulmonary bypass at moderate hypothermia without deep hypo- thermic circulatory arrest is microemboli. The microembolic load is proportional to the cerebral blood flow in addition to other factors such as the type of oxygenator used and failure to use an arterial line filter. Several studies have demonstrated that use of the $\mathrm{pH}$-stat strategy is associated with greater cerebral blood flow than is required for the brain's metabolic requirements. This has been termed "luxury perfusion." 14,15 Thus it is important that the results of the current study not be extrapolated to situations in which circulatory arrest and deep hypothermic temperatures are not used.

In previous studies with this piglet model, ${ }^{3,9}$ we found that oxygen and glucose consumption are insensitive end points for the study of recovery after deep hypothermic circulatory arrest. Despite the marked difference in recovery rate of high-energy phosphates, no demonstrable differences in the CMR- $\mathrm{O}_{2}$ and CMR-gluc were apparent among the four groups. The discrepancy between oxygen consumption and ATP levels may indicate increased ATP consumption in the alpha-stat animals. However, it is important to note that calculation of the CMR-O $\mathrm{O}_{2}$ and CMR-gluc was based on jugular bulb samples and not sagittal sinus blood and the result may not directly reflect cerebral parenchymal aerobic glycolysis.

There are important limitations in this study that limit the conclusions that may be drawn. The acute cerebral metabolic findings have not been correlated with neurologic outcome. Nevertheless, Robbins, Balaban, and Swain ${ }^{16}$ have reported a close relation between cerebral ATP stores and electroencephalographic recovery after circulatory arrest. Coles and 

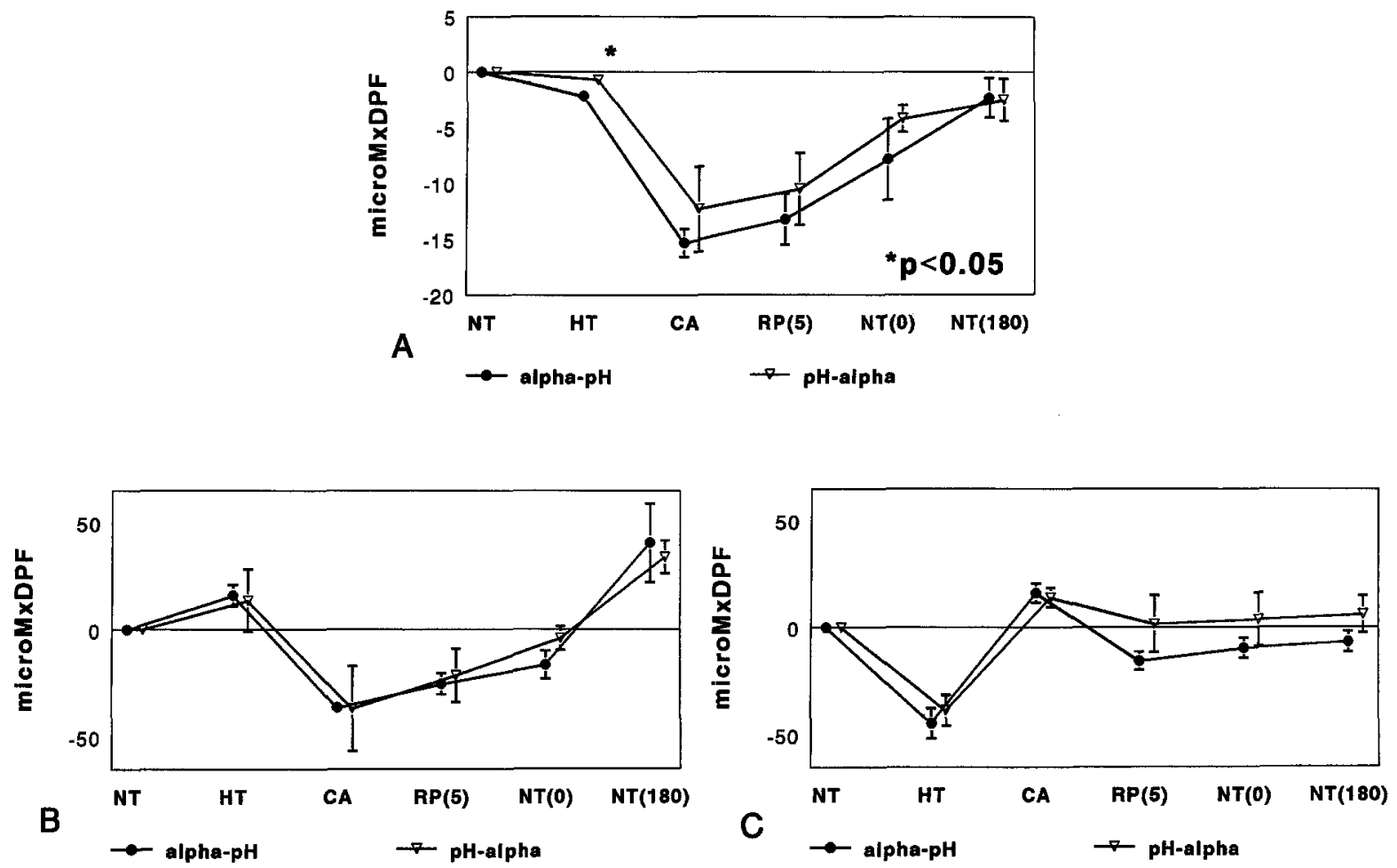

Fig. 5. Near infrared spectroscopy. A, Recovery of redox state of cytochrome aa 3 . B, Recovery of oxygenated hemoglobin. C, Recovery of reduced hemoglobin. DPF, Differential pathlength factor; NT, normothermic cardiopulmonary bypass; $H T$, hypothermic cardiopulmonary bypass; $C A$, circulatory arrest; $R P(5)$, 5 minutes after reperfusion and rewarming; $N T(0)$, after 45 minutes of rewarming, when normothermia (nasopharyngeal temperature $>35^{\circ} \mathrm{C}$ ) was achieved; $N T(180)$, normothermia for 180 minutes.

colleagues ${ }^{17}$ also found that more alkaline $\mathrm{pH}$ immediately before deep hypothermic circulatory arrest correlated with delay in recovery of somatosensory evoked potentials. A prospective clinical study of circulatory arrest at our institution has revealed a correlation between longer electroencephalographic recovery time after circulatory arrest and worse developmental outcome at age 1 year (unpublished data from the Boston Circulatory Arrest Study). In our current clinical practice we are prospectively randomizing patients between alpha-stat and $\mathrm{pH}$ stat strategies and are conducting neurologic and developmental follow-up studies.

In summary, these data suggest that there are mechanisms in effect during both the cooling and rewarming phases of cardiopulmonary bypass used in association with deep hypothermic circulatory arrest that could contribute to an improved cerebral outcome with $\mathrm{pH}$-stat relative to more alkaline strategies when the use of circulatory arrest is unavoidable.
We thank Laura Young for preparation of the manuscript and Mark A. Cioffi, MAT, and Gene L. Walter, BS, for their technical assistance.

\section{REFERENCES}

1. Jonas RA, Bellinger DC, Rappaport LA, et al. Relation of $\mathrm{pH}$ strategy and developmental outcome after hypothermic circulatory arrest. J THORAC CARDIOVASC SURG 1993;106:362-8.

2. Bellinger DC, Wernovsky G, Rappaport LA, et al. Cognitive development following repair as neonates of transposition of the great arteries using deep hypothermic circulatory arrest. Pediatrics 1991;87: 701-7.

3. Aoki M, Nomura F, Stromski ME, et al. Effects of pH on brain energetics after hypothermic circulatory arrest. Ann Thorac Surg 1993;55:1093-103.

4. Severinghaus JW. Respiration and hypothermia. Ann N Y Acad Sci 1959;80:384-94.

5. Bing OH, Brooks WW, Messer JV. Heart muscle viability following hypoxia: protective effect of acidosis. Science 1973;180:1297-8.

6. Bonventre JV, Cheung JY. Effects of metabolic aci- 
dosis on viability of cells exposed to anoxia. Am J Physiol 1985;294:C149-59.

7. Nayler WG, Panagiotopoulos S, Elz JS, Daly MJ. Calcium-mediated damage during postischemic reperfusion. J Mol Cell Cardiol 1988;20(Suppl 2):41-54.

8. Matsuda N, Kuroda H, Mori T. Beneficial actions of acidotic initial reperfusate in stunned myocardium of rat hearts. Basic Res Cardiol 1991;86:317-26.

9. Kawata H, Fackler JC, Aoki M, et al. Recovery of cerebral blood flow and energy state in piglets after hypothermic circulatory arrest versus recovery after low-flow bypass. J Thorac Cardiovasc Surg 1993; 106:671-85.

10. Heymann MA, Payne BD, Hoffman JIE, Rudolph AM. Blood flow measurements with radionuclidelabeled particles. Prog Cardiovasc Dis 1977;20:55-79.

11. Kost GJ. pH standardization for phosphorus-31 magnetic resonance heart spectroscopy at different temperatures. Magn Reson Med 1990;14:496-506.

12. Swan $\mathbf{H}$. The hydroxyl-hydrogen ion concentration ratio during hypothermia. Surg Gynecol Obstet 1982; 155:897-912.

13. Swain JA, McDonald TJ, Robbins RC, Balaban RS. Relationship of cerebral and myocardial intracellular $\mathrm{pH}$ to blood $\mathrm{pH}$ during hypothermia. Am J Physiol 1991;260:H1640-4.

14. Lassen NA. Luxury perfusion syndrome and its possible relation to acute metabolic acidosis localized within the brain. Lancet 1966;2:1113-5.

15. Henriksen L. Brain luxury perfusion during cardiopulmonary bypass in humans: a study of cerebral blood flow response to changes in $\mathrm{CO}_{2}, \mathrm{O}_{2}$, and blood pressure. J Cereb Blood Flow Metab 1986;6:366-78.

16. Robbins RC, Balaban RS, Swain JA. Intermittent hypothermic asanguineous cerebral perfusion (cerebroplegia) protects the brain during prolonged circulatory arrest. J ThoraC CARDIOVASC Surg 1990;99: 878-84.

17. Coles JG, Taylor MJ, Pearce JM, et al. Cerebral monitoring of somotosensory evoked potentials during profoundly hypothermic circulatory arrest. Circulation 1984;70(Suppl):I96-102.

\section{Discussion}

Dr. Jorge A. Wernly (Albuquerque, N.M.). This is another excellent experimental study on cerebral protection from the Boston Children's Hospital group in which the deep hypothermic circulatory arrest pig model was used. The results of this experiment quite convincingly, in my opinion, demonstrate that in this animal model the $\mathrm{pH}$ stat strategy provides more rapid recovery of brain highenergy phosphate stores and pHi after hypothermic arrest. These results provide additional support to the previous experimental and clinical observations that suggest that the pH-stat strategy provides an overall effective cerebral protection during deep hypothermia. If these observations are correct, and they are validated by well-designed clinical protocols, it will mean that the use of the alphastat strategy, which is the $\mathrm{pH}$ strategy most commonly used in clinical practice, and incidentally by all ectothermic animals, will have to be abandoned for patients undergoing deep hypothermia.

The clinical use of the alpha-stat strategy was popularized in the early 1980 s when it was recognized that protein configuration, enzymatic activity, ionization of substrates, movement of metabolites across membranes, and overall intracellular metabolism were better preserved with use of this $\mathrm{pH}$ strategy. If one focuses on preservation of organ function under hypothermia, there is little doubt that enzymatic function is better preserved when the $\mathrm{pH}$ is allowed to become more alkalotic as the temperature decreases, mimicking the behavior of water, "in vitro" blood, and that of all ectothermic animals. In sharp contrast to this biologic behavior is the $\mathrm{pH}$-stat strategy in which the normothermic $\mathrm{pH}$ is kept constant at all temperatures. Interestingly enough, the animal world gives us an animal model for $\mathrm{pH}$-stat strategy because that is exactly the $\mathrm{pH}$ temperature regulation exhibited by hibernating mammals. Hibernating mammals-the hamster, the squirrel, or the bear-keep a $\mathrm{pH}$ of 7.4 even at temperatures as low as $5^{\circ} \mathrm{C}$.

Why do they behave that way? It may well be that if preservation of cellular energy stores and structure are the main goals, the $\mathrm{pH}$-stat strategy affords better protection without necessarily providing the best environment to maintain function. It has been suggested, and these experiments support the contention, that hibernating animals, by adopting the "wrong" slightly more acidotic $\mathrm{pH}$, further decrease the enzymatic function already depressed by hypothermia.

The study of $\mathrm{pH}$ temperature regulation across evolution is fascinating. This is particularly so when one focuses on the regulation of $\mathrm{pHi}$, which is even more complex and probably more important than the regulation of the extracellular pH. It is known that hibernating animals keep the $\mathrm{pHi}$ of nonfunctioning organs (brain and muscle) at normothermic levels ( $\mathrm{pH}$-stat strategy) whereas, very interestingly, they allow the $\mathrm{pHi}$ of functioning organs (heart and liver) to become more alkalotic following the alpha-stat strategy. This observation brings me to my first question. Why did the pHi of the brain of the animals treated with the $\mathrm{pH}$-stat strategy (group P-P) become alkalotic even though the $\mathrm{pHi}$ was approximately 7.4 during cooling?

Dr. Hiramatsu. This is a difficult question. Presumably, it is in some way related to the function of the cation membrane transport enzymes that regulate $\mathrm{pHi}$ according to an alpha-stat strategy even though the extracellular environment is following a $\mathrm{pH}$-stat strategy. Unfortunately our study does not provide any information about these specific mechanisms.

Dr. Wernly. It is interesting to see that the pHi could not be controlled in the laboratory in the same way that animals do it in nature. Perhaps it may have something to do with the rate of cooling or depth of cooling. As you know, some of these animals keep their temperatures as low as $5^{\circ} \mathrm{C}$. The data presented here are quite provocative. The concept that $\mathrm{pH}$-stat strategy should be adopted. for patients undergoing deep hypothermia is intuitively 
attractive. What are your thoughts, and those of your group, about the clinical application of this $\mathrm{pH}$ strategy?

Dr. Hiramatsu. We are currently comparing the $\mathrm{pH}$ stat strategy with alpha-stat strategy in a prospective randomized clinical trial. The developmental and neurologic end points of that study will be the same as those of our previous prospective clinical study in which we compared circulatory arrest with continuous low-flow bypass. One specific clinical situation in which we do now routinely use the pH-stat strategy is in the presence of multiple aortopulmonary collateral vessels such as occurs with tetralogy of Fallot with pulmonary atresia. Under these circumstances, a more alkaline strategy such as alphastat will exacerbate runoff to the lungs through the collateral vessels because of the pulmonary vasodilation that results from the more alkalotic strategy. It was this subgroup of patients who had a high incidence of choreoathetosis at our hospital after the introduction of alpha-stat in 1985.

Dr. Wernly. Deep hypothermia has been invaluable in providing a combination of excellent exposure and cerebral protection. Usually, new techniques like deep hypothermic low-flow bypass and deep hypothermic retrograde cerebral perfusion will change the indications for deep hypothermic circulatory arrest. However, deep hypothermic circulatory arrest will continue to be used for many procedures. I will submit that the condition of patients in the operating room undergoing hypothermia is much closer to that of a hibernating bear than to that of a fish swimming in a cold river. I hope that in the next few years we will be able to answer the question of which is the better $\mathrm{pH}$ strategy to follow in deep hypothermic situation.

Dr. Julie Swain (Las Vegas, Nev.). My question relates to the conclusion that the $\mathrm{pH}$ improves faster with $\mathrm{pH}$-stat regulation. The problem I have is a lack of $p$ value points on the graph that you showed. It seems that $\mathrm{pH}$-stat recovery is faster because it starts off more acidotic. How do you explain the conclusion that alpha-stat produces more acidosis in the earlier points of recovery? It appears that the $\mathrm{pH}$ ends up the same and that alpha-stat produces a higher $\mathrm{pH}$ during arrest and in the earlier part of reperfusion.

Dr. Hiramatsu. The $p$ value for the mean rate of recovery of $\mathrm{pHi}$ in the first 30 minutes of reperfusion was 0.026 with the P-P group showing significantly more rapid recovery toward the baseline value than the A-A group. We agree with you that the exact significance of this finding is unclear; nevertheless, we can extrapolate from other studies of circulatory arrest that have demonstrated that delayed recovery of the electroencephalogram and somatosensory potential as described by the Mount Sinai and Toronto groups has been associated with a worse neurologic outcome. This was also true in the Boston Circulatory Arrest clinical study in which delayed electroencephalographic recovery correlated with a worse developmental outcome at 1 year. But, as you correctly point out, a lower absolute $\mathrm{pHi}$ occurs with the $\mathrm{pH}$-stat strategy relative to the alpha-stat strategy.

\section{1-800-55-MOSBY}

This number links you to the full text of articles published in over 25,000 journals, including all Mosby journals. MOSBY Document Express $^{\mathrm{TM}}$, a rapid response information retrieval service, provides quick turnaround, 24-hour availability, and speedy delivery methods. For inquiries and pricing information, call our toll-free, 24-hour order line: 1-800-55-MOSBY; outside the United States: 415-259-5046; fax: 415-259-5019; E-mail: mosbyexp@class.org.

MOSBY Document Express ${ }^{\mathrm{TN}}$ is offered in cooperation with Dynamic Information Corp. 